\title{
“RETORNO DE LA CIVILIZACIÓN” A QUIRIGUÁ: \\ ARQUEOLOGÍA MAYA Y LOS JUEGOS DE PODER Y \\ PRestigio en Centroamérica en los Siglos XIX Y \\ $\mathrm{XX}$
}

\author{
“ThE RETURN OF CIVILIZATION” TO QUIRIGUÁ: MAYA \\ ARCHAEOLOGY AND THE PLAY FOR POWER AND \\ prestige in Central America in the nineteenth \\ AND TWENTIETH CENTURY
}

\section{Markéta Kř́ǐzová *}

Resumen: Estudiar la historia de las exploraciones arqueológicas de la localidad de Quiriguá, Guatemala, sirve como un punto de partida hacia reflexiones más generales sobre la naturaleza de la disciplina arqueológica, ayudando a situarla en un contexto sociopolítico mucho más amplio. Desde sus inicios en el siglo XIX, la arqueología se ha encontrado bajo la influencia de las ideologías hegemónicas de la época, el nacionalismo y el imperialismo. Estas influencias moldearon la naturaleza de la investigación arqueológica y las presentaciones de sus resultados; sin mencionar algunos otros factores como la competencia institucional y las ambiciones personales de quienes llevaban a cabo las investigaciones, que también se vieron reflejadas en las labores científicas de las expediciones. Específicamente en el caso de Quiriguá, la actitud posesiva de los primeros exploradores (John Stephens, Alfred Mauldsay, etc.) y el subsecuente dominio que ejerció la compañía United Fruit en la zona, así como las aspiraciones de diferentes instituciones científicas estadounidenses (como la School of American Archaeology o la Carnegie Foundation, por decir algunas), son analizadas respecto a las interpretaciones que generaron

\footnotetext{
* Afiliada al Centro de Estudios Ibero-Americanos, Facultad de Filosofía, Universidad Carolina, la autora se especializa en las líneas de investigación: historia del pensamiento científico e historia de la ciencia. identificador ORCiD: 0000-0003-1914-3477. Correo electrónico: marketa.krizova@ff.cuni.cz.

Fecha de recepción: 2801 19; 2a. versión: 2603 19; Fecha de aceptación: 200619.
}

(c) BY-NC-ND Páginas 171-202

julio-diciembre 2019, vol. 6

núm. 2 (13) ISSN: 2007-7610 
sobre la civilización maya precolombina. El presente texto no aspira a ser un análisis exhaustivo de los problemas que la relación entre el nacionalismo, el imperialismo y la arqueología, causaron en Latinoamérica; sino la mera presentación de un fenómeno que ayude a ilustrar la necesidad de considerar siempre el contexto político, social y cultural en el que se producen las "verdades" científicas.

Palabras clave: mayas, arqueología, historia de la arqueología, historia de pensamiento cientifico, Quiriguá, United Fruit Company.

Abstract: A case study of the history of exploration of the archaeological locality known as Quirigua, in the lowlands of Guatemala, serves as a starting point for more general considerations on the nature of archaeology as a scientific discipline in its wider social and political context. Archaeology had been, since its commencement in the $19^{\text {th }}$ century, under the influence of the reigning ideologies of the day, nationalism and imperialism, and this strongly shaped the nature of the research and the presentation of its outcomes; not to mention many other diverse factors, such as institutional competition and personal ambitions, that reflected on the scientific endeavors. On the basis of the case of Quiriguá, the possessive attitude of the early explorers (John Stephens, Alfred Mauldsay etc.) and the subsequent domination of the site by the United Fruit Company, as well as the aspirations of North American scientific institutions (School of American Archaeology, Carnegie Foundation) are explored with respect to the interpretations of the pre-Colombian Maya civilization coined by them. The present text does not aspire to a thorough analysis of the problem of relations between nationalism, imperialism and archaeology in Latin America, but rather a presentation of one specific case illustrative of the basic premise of the necessity to always take into account the broader context in which the scientific "truths" are produced.

Keywords: Mayas, archaeology, history of archaeology, history of scientific thought, Quirigua, United Fruit Company. 


\section{Introducción ${ }^{1}$}

La ciudad precolombina que hoy día se conoce como Quiriguá - no sabemos su nombre original, éste lo lleva según la comunidad en sus alrededores, fundada en el tiempo colonial- era, en el período precolombino, uno de los centros urbanos importantes de las tierras bajas en el sudeste de Guatemala. Fue fundada alrededor del año $426 \mathrm{~d}$.C, en el fértil valle aluvial del río Motagua, cerca de su confluencia con otras dos corrientes. La ubicación de la ciudad daba a sus soberanos una base económica en forma de una agricultura intensiva y, a la vez, la posibilidad de controlar e involucrarse en el comercio de larga distancia; aún más, era estratégica gracias a la cercanía de yacimientos de materiales apreciados por los mayas, tales como el jade y la obsidiana. La rivalidad, a largo plazo, con otra ciudad rica y poderosa, Copán, terminó con la derrota de Copán y dio como resultado el período del máximo auge de Quiriguá, antes de que en los siglos IX y X todas las tierras bajas guatemaltecas se vieran afectadas por la crisis socioeconómica que llevó al abandono de los asentamientos urbanos y a la interrupción del desarrollo cultural (Sharer y Traxler, 2012; Looper, 2003).

Hoy día, Quiriguá figura en la lista de los destinos turísticos más populares de Guatemala, además de estar, desde 1981, inscrita en la lista del patrimonio cultural de la UNESCO. Ha sido el objeto de interés de arqueólogos y etnohistoriadores por más de un siglo; de hecho, fue una de las primeras localidades mayas sujetas a la exploración científica por parte de los intelectuales europeos y estadounidenses. Las tempranas investigaciones, sin embargo, no solamente contribuyen al conocimiento de la historia y cultura de los constructores y habitantes de Quiriguá, sino que también revelan las motivaciones extra-académicas de aquellos que, financiera e institucionalmente, respaldaban, realizaban o comentaban las excavaciones en la localidad. El caso de Quiriguá y sus exploraciones demuestra claramente que la historia de la ciencia no puede entenderse fuera del contexto social

\footnotetext{
${ }^{1}$ El presente artículo tuvo su origen en la Universidad Carolina, dentro del proyecto "PROGRES Q09: Historia - Llave al entendimiento del mundo globalizado”. La primera versión, muy breve, se publicó en 2016 bajo el título "Návrat civilizace do Quiriguá: United Fruit Company a počátky mayské archeologie“" Dějiny a současnost 38:2, 19-23. Se presenta aquí una versión ampliada y actualizada. Si no es indicado otra manera, las traducciones de fuentes en inglés y alemán son de la autora.
} 
y económico, que influía de modo considerable en los métodos, técnicas y modelos interpretativos ${ }^{2}$.

El presente texto no tiene como objetivo un análisis exhaustivo de la relación entre nacionalismo, imperialismo y arqueología en América Latina (o en Guatemala), ni propone un nuevo enfoque teórico sobre el problema de la producción y configuración del conocimiento. Es simplemente un estudio de caso que aspira a ilustrar, a base de la documentación de la época, una premisa básica pero crucial: la necesidad de siempre tomar en cuenta el amplio contexto político, social y cultural en el que se producen las “verdades" científicas.

\section{Los pioneros en la selva}

A pesar de los relativamente numerosos testimonios sobre ruinas monumentales hundidas en las selvas tropicales del sur de México y de Centroamérica, hasta la mitad del siglo XIX los hombres interesados en las "antigüedades" americanas no prestaban mucha atención a los mayas, en contraste al interés en los aztecas o incas (Keen, 1971). A pesar de algunos testimonios del tiempo colonial y de las primeras décadas de la independencia (Brunhouse, 1989; Graham, 1963), fue solamente después del glorificado viaje de John Stephens y Frederick Catherwood en la década de 1840 , que la naciente comunidad transnacional arqueológica notó la existencia de los mayas. Quiriguá fue una de las ciudades descritas en los Incidentes de viaje en Centroamérica, Chiapas y Yucatán de Stephens, el best seller del siglo en los Estados Unidos y la Europa Occidental. Cabe aclarar que aunque Stephens mismo no visitó las ruinas de Quiriguá, a Catherwood lo asombraron la grandiosidad y finura de sus monumentos de piedra, estelas y estatuas (Stephens, 1971/2: 101-106; Catherwood, 1844: 8-9).

En contraste con muchas opiniones contrarias de su tiempo, Stephens estaba convencido que los campesinos mayas asentados en los alrededores de las ruinas eran los descendientes de sus constructores. Aunque en sus descripciones a menudo aparecían alusiones a las civilizaciones perdidas del Viejo Mundo, como Egipto, Grecia o Babilonia, éstas no eran comparaciones directas o argumentos a favor de la búsqueda del origen de los mayas fuera del continente americano. Al contrario, la insistencia de Stephens con respecto a la originalidad de la cultura maya posicionaba su libro de viajes al lado de las obras de Henry Rowe Schoolcraft o James Fenimore Cooper, que

${ }^{2}$ Para el posicionamiento del estudio arqueológico en procesos sociales y ambiciones nacionales e imperiales, véase Díaz-Andreu, 1999 y Trigger, 1984. 
invocaban el gran pasado indígena como una de las fuentes claves para la especificidad de la identidad y la cultura de la joven república estadounidense, en contraste con los esfuerzos por equipararse con la tradición europea (Harvey, 2001: 162). Durante la primera mitad del siglo XIX, Egipto se volvió enormemente popular entre los intelectuales europeos gracias a la expedición napoleónica y los subsecuentes hallazgos sensacionales de Champollion. Los museos competían por las adquisiciones de artefactos y los historiadores buscaban la continuidad en el desarrollo cultural de la región. También a los estadounidenses los afectó la "fiebre egipcia", pero gracias a Stephens (entre otros) después de 1850 comenzaron a buscar sus propias raíces, en vez de tratar de apoderarse simbólicamente de las de fuera. En las palabras del mismo Stephens, "los moldes del Partenón son considerados monumentos preciosos, y los de Copán resultarían lo mismo para Nueva York” (Stephens, 1971/1: 45; Evans, 2004).

Más allá de atraer la atención de "anticuarios" a Centroamérica, al alabar la hermosura de la arquitectura maya, Stephens asumió un papel singular dentro de las iniciales aspiraciones estadounidenses por una emancipación identitaria y, además, de la hegemonía hemisférica. En palabras de Juan Ortega y Medina, Stephens era uno de los protagonistas del "monroismo científico" que buscaba sustentar la dominancia de los Estados Unidos en el sur del continente dentro del marco del Destino Manifiesto (Ortega y Medina, 1962), integrando a la vez el pasado maya al presente de la América del Norte. "La belleza de la escultura, la solemne quietud que se perturbaba únicamente por la trepa de los monos y el parloteo de los loros, la desolación de la ciudad, y el misterio sobre ella suspendido" producía en Stephens "un interés mayor, si fuera posible, que el que yo jamás sentí en medio de las ruinas del Antiguo Mundo" (Stephens, 1971/1: 48), demostrándose así la inherente afinidad entre los "americanos" de varios períodos históricos. La idea de que América poseyera su propia civilización indígena, cuyos antiguos logros rivalizaran con cualquiera encontrada en el territorio europeo, capturaba la imaginación de los lectores estadounidenses.

Stephens no llegó a Centroamérica como viajero privado, o representante de una institución científica, sino como "delegado confidencial" del presidente estadounidense ante la Confederación Centroamericana, con la principal tarea de negociar con los representantes centroamericanos y explorar el terreno para la eventual construcción de una vía férrea interoceánica. Esto 
abriría a los Estados Unidos la vía hacia la dominancia económica, política y cultural en el Atlántico, en el Pacífico y también en el istmo centroamericano (Shoonover, 1991). Las actividades de Stephens en la selva se ajustaban bien a tales proyectos imperialistas, legitimados no solamente por la retórica de la historia compartida, sino también por una supuesta superioridad civilizacional. El pasado maya resultaba, de las presentaciones de Stephens, como un rico tesoro, rescatado de la selva y de manos bárbaras y desdeñosas. "La ignorancia, el descuido y la indeferencia (sic) de los habitantes de Hispano América sobre este asunto es cosa que admira", se quejó Stephens (1971/1: 54). La magnificencia de las ruinas se pone, pues, en contraste con la barbarie de los habitantes de la región y los estadounidenses son presentados como los únicos capaces de valorar la grandeza histórica americana (Lenz, 2012).

De hecho, en las décadas anteriores a su llegada hubo un intenso esfuerzo arqueológico de parte del gobierno guatemalteco. Ya en 1831, y a pesar de la pésima situación económica del país, el presidente Mariano Gálvez anunció la creación de un museo nacional y se preocupó por recopilar información sobre sitios arqueológicos, argumentando que "la historia del Estado debe ser ennoblecida con las descripciones de los monumentos y antigüedades" (Chinchilla Mazariegos, 1993: 2). La motivación era prácticamente la misma que la de las investigaciones norteamericanas, la búsqueda de raíces y el esfuerzo por legitimar la existencia nacional. Más aún, las élites guatemaltecas sentían su deficiencia frente a México, cuya capital se hallaba sobre la metrópoli azteca y cuyos patriotas tenían a su disposición numerosos testimonios coloniales sobre la grandeza de sus predecesores indígenas. Todo esto ignoraban por completo Stephens y sus seguidores, quienes, en contraste, ostentaban la "primacía" de sus visitas a los sitios arqueológicos, alcanzados a precio de mil dificultades y sufrimientos. Quiriguá, por ejemplo, de veras estaba ausente de la documentación colonial y probablemente era desconocida, en contraste con Palenque y otras localidades. No obstante, también en las descripciones de casi todas las ciudades mayas prevalecía la figura del intelectual valiente que solitariamente enfrentaba los peligros del "terreno virgen"” selvático: malaria, mosquitos, indios bárbaros y políticos locales ignorantes que impedían desvelar tesoros hundidos y misterios de la antigüedad.

$\mathrm{Su}$ repetido esfuerzo por obtener, por medio de la compra, monumentos o incluso ciudades enteras y transportarles a Nueva York, donde aspiraba a

\footnotetext{
${ }^{3} \mathrm{Al}$ describir su viaje hacia Quiriguá, Stephens relató: "El campo era enteramente nuevo; no había guías escritas ni conductores; todo era terreno virgen” (Stephens, 1971/1: 43).
} 
Figura 1. Guatemala, Quiriguá

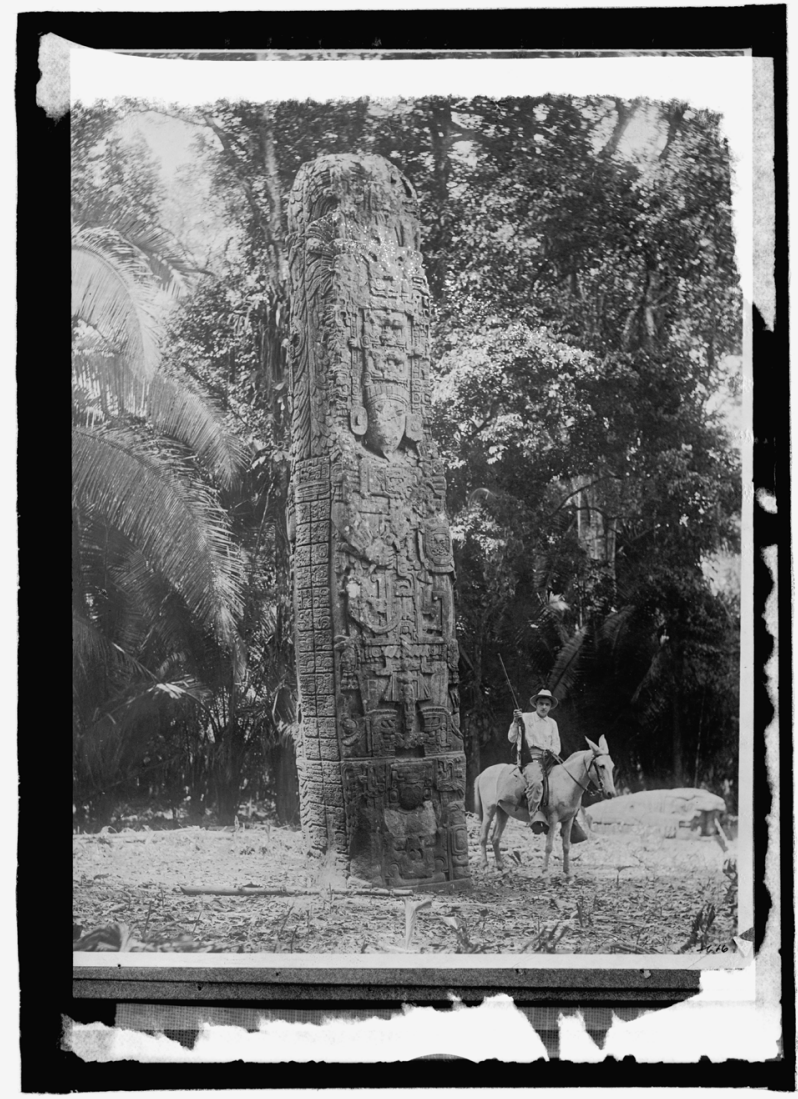

Fuente: (Library of Congress, 1908)

construir el "Museo Nacional de Antigüedades Americanas" (Stephens, 1971/1: 40), captaba muy bien la postura de Stephens hacia la herencia cultural centroamericana. Quiriguá era uno de estos selectos bienes. Al narrar la historia de su esfuerzo por obtenerlas, Stephens revivió una vez más el tema de la ignorancia de la población centroamericana. Según narra, el propietario del terreno en el que se encontraba la zona arqueológica aceptó su oferta, pues "en su país no se apreciaban esas ruinas, y él se sentiría dichoso de contribuir a la causa de la ciencia en el nuestro" (Stephens, 1971/2: 106). Al final Stephens desistió del proyecto, no sin antes retirar algunos de los dinteles tallados y otros objetos de tamaño pequeńo (dichos objetos fueron destruidos, junto con los daguerrotipos de Catherwood, en el gran incendio de Nueva York en julio de 1842). Lerner (2005: 83) testifica bien este esfuerzo por apoderarse 
físicamente, no solamente de unas piezas aisladas, sino de ciudades enteras, del valor simbólico que tenía el artefacto antiguo para el público estadounidense y sus líderes.

Stephens mismo advertía que "los amantes del arte y de la ciencia en Europa podrían posesionarse de ellos; mas dichos monumentos y ruinas nos pertenecen por derecho propio; y decido que ellos deberían ser para nosotros" (Stephens, 1971/1: 106). De hecho, fue precisamente la publicación del libro de Stephens lo que motivó al primer ministro británico, Lord Palmerston, a enviar un despacho en 1851 al chargé d'affaires en Guatemala, Frederick Chatfield, en el que Palmerston hizo constar que:

sería deseable obtener para el Museo Británico algunas muestras de las esculturas de las ruinas de ciudades de Centroamérica. [...] Aparece en el reporte del Sr. Stephens que estas ruinas están cubiertas de árboles y otra vegetación y mantenidos en poca o ninguna estimación por los nativos del país, y pues parece probable que la dificultad más grande [...] consistirá en buscar el modo para transportarles hasta el lugar de embarcación.

Los artefactos precolombinos figuran en el despacho no como una fuente potencial del conocimiento científico, sino como objetos simbólicos, cuya apropiación fortalecería el prestigio de sus respectivos países en la competencia internacional. Más aún, Palmerston reiteró en lo que insistía Stephens: que para los habitantes de los países centroamericanos, los artefactos de piedra precolombinos "no tienen ningún valor en absoluto" (Aguirre, 2005: 62) ${ }^{4}$.

Tales argumentos fortalecerían el discurso legitimador del mundo occidental en la última fase de expansión colonial. Los habitantes de Centroamérica - o de América del Sur, África o Asia- se presentaban no solamente como carentes de capacidades para aprovechar los recursos naturales locales, sino también para conocer y estudiar adecuadamente su propia historia antigua. De hecho, el mismísimo interés en las ruinas prehistóricas se traducía en el discurso europeo y estadounidense de este tiempo como un signo de la pertenencia al más alto nivel civilizacional; mientras que el supuesto desinterés de parte de los "descendientes" de los constructores indígenas de las ruinas se interpretaba como prueba de su barbarie. El anhelo por "conocer" se consideraba una de las

\footnotetext{
${ }^{4}$ Para el texto completo del despacho de Palmerston, con base en la copia de la carta en el archivo gubernamental de Belice, véase Thompson (1936). 
características dominantes de la cultura europea (Salvatore, 2016; Kennedy, 2014).

Se confió la misión de obtener las piezas para el Museo Británico a dos naturalistas, el austríaco Karl von Scherzer y el alemán Moritz Wagner, quienes en el momento se hallaban en la fase final de su largo viaje a través de Centroamérica. A causa del estado de guerra entre Guatemala y Honduras, tuvieron que abandonar su plan original de visitar Copán y eligieron a Quiriguá como destinación alternativa. El reporte de Scherzer contiene descripciones dramáticas de su viaje "por el río Motagua, en el tallo hueco de un gigantesco árbol de cedro, [...] con dolores numerosos y considerables, que solamente pueden imaginarse los que conocen personalmente el carácter de América tropical. [...] Desde hace años, estas ruinas no han sido visitadas" (Scherzer, 1855). Se revivificó pues, una vez más - pero no la última- el tropo del "descubridor" de una ciudad ya descrita en detalle por Frederick Catherwood, reafirmando así el modo de apropiación conocido por los occidentales desde el siglo XVI (Alvarenga Ventulo, 2015). Al fin y al cabo el proyecto de transportar las estatuas fracasó a causa de las dificultades técnicas, pero Scherzer por lo menos las describió en detalle (Recinos, 1953-54).

Es interesante que, en contraste con Stephens, el viajero austríaco no valorara mucho a las antigüedades mayas desde el punto de vista artístico. Las consideraba "interesantes" para los que se preocupasen por desvelar los misterios de los orígenes de humanidad, pero

la industria y perseverancia de los que cubrieron tan grandes piezas de piedra con esculturas y sabían como mover estos monumentos colosales en el suelo tan blando [...] merece más admiración que la fantasía, gusto y capacidad de los artistas. [...] La disposición de figuras y ornamentos tanto como su ejecución detallada con sus figuras de animales, flores, hojas, ramas indica el estado bárbaro del arte. Nada en estas escultura indica gusto para la belleza (Scherzer, 1855: 230).

Para Scherzer, europeo enraizado en la estética tradicional (es decir, la griega), los mayas eran "otros" exóticos, que no formaban parte de su propia herencia cultural, pues los arqueólogos británicos y europeos de este tiempo estaban ocupados con la búsqueda de sus propios antepasados entre las tribus bárbaras 
Quiriguá...

de la antigüedad. Pero las estelas mayas, aún en esta situación, representaban un souvenir prestigioso.

Como comentó el Vizconde Mahon, secretario del Ministerio de Relaciones Exteriores británico, en un documento que inspiró en Palmerston el interés por la prehistoria del Nuevo Mundo: "las esculturas de las ruinas [centroamericanas] forman un noble suplemento de las que hemos obtenido recientemente en Niniveh" (Aguirre, 2005: 66). En contraste con otras partes del mundo, el imperio británico no logró establecer -y de hecho no aspiraba a hacerlo- el sistema colonial en América Latina (sin mencionar Belice, que por un largo período de tiempo careció del carácter formal de colonia). Así, la hegemonía se establecía a través de presiones económicas y culturales. El discurso arqueológico reforzaba y profundizaba el discurso del predominio natural europeo y la condescendencia hacia los habitantes originales. No por coincidencia en las narrativas de exploración se disminuía intencionadamente el papel de los guías y la mano de obra local ${ }^{5}$.

Figura 2. Guatemala, piedra de Quiriguá

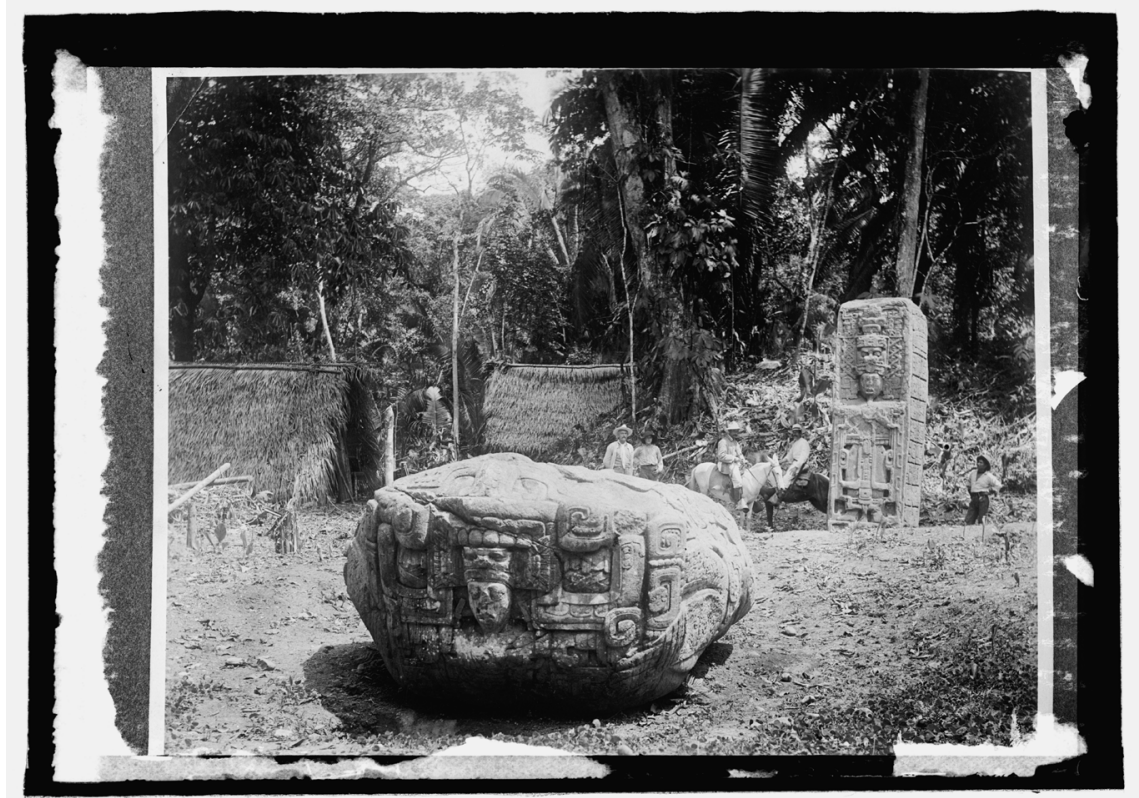

Fuente: (Library of Congress, 1908)

\footnotetext{
${ }^{5}$ Las imágenes de indolencia y los modos de "otrificación" en las narrativas arqueológicas reflejaban la tradición de libros de viajes en distintas partes tropicales del mundo (Vargas, 2008). Para la apropiación de los artefactos, véase Alvarenga Ventulo (2015).
} 
Los esfuerzos por apoderarse, no solo simbólica sino físicamente, de las reliquias mayas, continuaron en las últimas dos décadas del siglo XIX en las expediciones del británico Alfred Maudslay, que eligió Quiriguá como su primera parada en 1881 . La monumentalidad de sus palacios y estatuas le asombró de tal manera que decidió dedicar el resto de su vida al estudio de los enigmas de la cultura maya. Como a sus predecesores, a Maudslay le escandalizó lo que percibía como una falta de conciencia histórica por parte de los centroamericanos, y decidió preservar los testimonios de la antigua civilización para la humanidad y para su nación. No aspiraba, sin embargo, al transporte de los artefactos de piedra originales a Londres. En vez de esto, hizo moldes y fotografías. El uso de la fotografía durante las expediciones arqueológicas a fines del siglo XIX ganaba en popularidad y se convertía en otro de los modos de apropiación simbólica de las regiones ultramarinas, la expansión de horizontes de la población y la imposición de estándares estéticos e intelectuales occidentales sobre la naturaleza y la humanidad no europea (Maxwell, 2000; Nilsen, 2011).

Las fotos tomadas por Maudslay en 1892 se presentaron al público durante la exhibición internacional de Sevilla, para la conmemoración del 400 aniversario del descubrimiento de América. Así, se ubicaron los retratos de las ruinas precolombinas dentro del sistema occidental del triunfalismo colonial. El año siguiente, durante la mucho más grandiosa y celebrada Exposición Mundial Colombina de Chicago -en una prueba más del hecho de que las ambiciones imperiales en este tiempo ya se habían trasladado del Viejo al Nuevo Mundo- Maudslay presentó una nueva colección de fotos para el "Pabellón guatemalteco". Después, Maudslay regaló la mayoría de sus fotos y moldes al Museo Británico; además, el Field Museum de Chicago compró parte de la colección de fotografías, confirmándose así la persistente "guerra" de las instituciones británicas y estadounidenses por objetos para exhibir al público (Graham, 2002; Shields, 2015). Maudslay también cultivaba la retórica de la búsqueda de ruinas hundidas en la selva y los obstáculos que enfrentaban los miembros de la expedición, antes de que -en lo que representara un triunfo de la técnica-el "botín científico" se transportara a Europa. Sus descripciones acentuaban la "otredad" y el carácter grotesco de las representaciones de piedra, "exageradas hasta el grado de ser demasiado difícil reconocerlas" (Maudslay, 1886: 587-589). 
Pese a su atractivo visual, las antigüedades mayas se hallaban relegadas al nivel de la "naturaleza". Por ejemplo, es característica la manera en que Maudslay incluye y describe las ruinas mayas en una serie de 63 libros dedicados a la flora y fauna de América Central: Biologia Centrali-Americana (Maudslay, 1899-1902, Maudslay y Maudslay, 1899). Así como en el estudio de la naturaleza, el poder del observador "culto" consistía en su - supuestamente exclusiva - capacidad de nombrar, clasificar y analizar lo visto. Pero el viaje científico también se traducía en actos hegemónicos concretos: los reportes de Maudslay en Centroamérica provocaron, en los ańos ochenta, el esfuerzo del gobierno británico por construir una vía férrea de Belice a Guatemala (Aguirre, 2012: 247).

\section{Entra a escena la United Fruit Company}

En 1909, grandes extensiones de tierra en la parte central de Guatemala, y también en los terrenos de bajo Quiriguá, pasaron a ser propiedad de la compañía estadounidense United Fruit Company (UFCo). Formada en 1899 por la unión de varias empresas bananeras en operación, tras apenas una década la compañía ya controlaba el $80 \%$ de la producción del fruto en Centroamérica y se expandía también en construcciones de infraestructura: líneas telegráficas, puertos y, especialmente, líneas férreas, indispensables para transportar productos perecederos a los consumidores. Para Guatemala, la más importante de estas empresas era la International Railways of Central America, que era propietaria de la totalidad de los ferrocarriles del país. Gracias a su control sobre la infraestructura y sobre gran parte de las exportaciones de los Estados centroamericanos, la compañía United Fruit ganó una posición soberana, y también una fama malvada, debido a las proverbiales duras condiciones en las plantaciones, al atamiento de los obreros a través del endeudamiento permanente, así como intervenciones en los asuntos políticos.

Por su parte, la compañía se presentaba para afuera como "portador de la luz" y embajadora de los valores estadounidenses, abriendo las puertas del progreso a las sociedades del sur. Ostentativamente construía para sus empleados hospitales y escuelas, contribuía a la investigación de la cura de la malaria y otras enfermedades tropicales, que tomaban su cuota de entre los obreros y así rebajaban las ganancias. En los textos promocionales, se pintaba a las plantaciones como enclaves de paz, orden, prosperidad y desarrollo cultural en una región turbulenta y azotada por revoluciones, pobreza e ignorancia 
(Colby, 2011; Dosal, 1993). Quiriguá debía asumir el papel del escaparate principal de tal esfuerzo civilizador.

Poco después de la compra de terrenos sobre los que se hallaban las ruinas, se apartaron 80 acres para un "parque tropical, [...] único en el mundo", que según las palabras del folleto promocional de la United Fruit Company (Adams, 1914: 204), sería una combinación de jardín botánico y museo al aire libre donde los representantes más altos de la compañía podrían pasar sus vacaciones, disfrutando del paisaje y metiéndose en el trabajo de restauración y despeje de las estructuras. Al año siguiente la UFCo firmó un acuerdo con una institución prominente, la Escuela de Arqueología Americana (School of American Archaeology, SAA). Esta institución se había establecido poco antes, en 1907, con sede en Santa Fe en Nuevo Mexico, como una rama del Instituto Arqueológico de América (Archaeological Institute of America, AIA), que desde 1879 y a través de sus sucursales en Roma, Atenas y Jerusalén, apoyaba la arqueología bíblica y de la Antigüedad Clásica, pero que desde los comienzos del siglo XX se hallaba bajo una presión creciente por cultivar también la arqueología del continente americano (Fowler, 2000; Lewis y Hagen, 2007). El proyecto de Quiriguá fue, pues, el resultado directo del creciente patriotismo o regionalismo de los patrocinadores de la arqueología estadounidense. La SAA enviaba profesionales, bajo la dirección Edgar Lee Hewett, para realizar excavaciones sistemáticas. Después de la segunda temporada, la United Fruit Company pagaba parte de los gastos y, además, ponía a la disposición del equipo el transporte, el alojamiento en las instalaciones bananeras del lugar y, de entre los peones, proporcionaba trabajadores para asistir a los arqueólogos.

Aparentemente, la iniciativa de realizar la investigación en Quiriguá salió de la UFCo, no de Santa Fe, aunque la SAA en este tiempo buscaba vías para penetrar en el territorio centroamericano. La recién fundada institución mantenía una competencia reńida con otras asociaciones arqueológicas estadounidenses, en especial la Escuela Internacional de Arqueología y Etnografía Americanas (International School of Archaeology and Ethnography, ISAE), que llegó a existencia en 1910 con base en un acuerdo de cooperación en el área del estudio de la prehistoria y de la cultura mexicanas, de algunas instituciones estadounidenses -entre ellas las universidades de Columbia, Pensilvania y Harvard, y la American Hispanic Society-, tanto como los gobiernos de México, Prusia y Francia. ${ }^{6}$ Debido al discurso nacionalista ${ }^{6}$ La ISAE dejó de existir en 1914, debido a la dificultad de mantener una institución de educación superior en plena insurrección. Cuando la situación política fue más estable, el 
mexicano, que en este tiempo alababa al Estado azteca como "predecesor" de la independencia nacional, las actividades de la ISAE centraban su atención en el Valle de México. En contraste, los mayas se hallaban al margen del interés de los intelectuales mexicanos (también debido a la devastadora "guerra de castas" del siglo XIX). El absoluto monopolio de sus competidores en la investigación en México central llevó a los arqueólogos de Santa Fe, ansiosos también de involucrarse en el estudio de grandes culturas precolombinas, a Guatemala, aunque ninguno de los miembros del equipo tenía experiencia previa en la región ${ }^{7}$. En el viaje de reconocimiento, Hewett se encontró con Victor M. Cutter, el representante regional de UFCo, y éste le ofreció la posibilidad de realizar las excavaciones en su plantación (Brunhouse, 1971: 52).

Puede verse entonces cómo, en primer lugar, el caso de Quiriguá demuestra que en las pugnas de la academia, los sitios arqueológicos asumían el papel del "botín", marcando el éxito del equipo en monopolizar los lugares más prestigiosos. Es cierto que, gracias a los especialistas de Santa Fe, desde 1911 se realizaba en Quiriguá una investigación arqueológica propiamente dicha, que empleaba los nuevos métodos (estratigrafía) y ponía especial interés en preservar y documentar minuciosamente el sitio. Incluso se hizo la restauración parcial de algunos edificios. Se trataba de la primera investigación de este tipo en toda la región maya. Precisamente en Quiriguá, en estos años, realizaron sus primeras experiencias en el campo de la arqueología americana Sylvanus G. Morley y Earl Morris. Tampoco podría afirmarse que la compañía bananera se involucrase directamente en el trabajo arqueológico. Daniel Schávelzon, en general demasiado crítico hacia lo que llamaba "un caso extremo de la interrelación entre política y arqueología”, recalcó que "de todas maneras Hewett nunca permitió que la empresa figurara como organizadora de las actividades académicas, sino que fuera su propia institución" (Schávelzon, 1988: 173). Al mismo tiempo, la obra arqueológica ciertamente servía como promoción de la compañía en el momento cuando comenzaba la fase de su expansión máxima y la crítica contra ella aumentaba. No solamente los mismos investigadores daban gracias por el "excelente apoyo" en los textos

medio intelectual mexicano cercano a la esfera del poder no manifestó interés por reanudar las actividades académicas, y el proyecto quedó en el olvido (Rutsch, 2000; Godoy, 1977; Urías Horcasitas, 2001).

${ }^{7}$ Sobre las competiciones institucionales en la academia norteamericana, tanto como los pleitos personales entre Edgar Hewett y los futuros fundadores de la ISAE (Alfred Tozzer y Franz Boas), véase Fowler (2003). 
publicados en los foros especializados y en las páginas de revistas populares (Hewett, 1912a; Hewett, 1912b; Hewett, 1916; Morley, 1912; Morley, 1913), tampoco los turistas que pasaban por la región se olvidaban de alabar a la compañía por su servicio a la humanidad. La vía férrea, nuevamente construida, facilitaba el acceso a las ruinas y el transporte de artefactos desde Centroamérica.

A la vez, la compañía había usado los argumentos de los arqueólogos para afrontar polémicas muy recientes. Se acentuaba, en comentarios sobre el progreso en la investigación, que los antiguos constructores de Quiriguá se habían asentado a propósito en las tierras bajas tropicales y prosperaban allí, en un ambiente que los críticos de la United Fruit Co. proclamaban inhabitable en vista de la masiva tasa de mortalidad de los peones en las plantaciones. A la vez, se vivificó la idea de que esta y otras ciudades guatemaltecas y mexicanas no habían sido construidas, o por lo menos diseñadas, por los mayas, sino por una "raza poderosa" que les precedía. Sobre esta última, se especulaba que eran los habitantes de la Atlántida, quienes buscaron refugio en el continente americano después de la destrucción de su bienaventurada isla, pero más tarde caerían víctimas de los mayas "bárbaros"8. Se asumió que el florecimiento civilizatorio solamente era posible en la localidad debido a la sabiduría y firmeza de estos soberanos, capaces de dirigir y administrar a los plebeyos.

Como explicó el autor del texto promocional, publicado con fondos de la UFCo en 1915, en el capítulo sintomáticamente titulado "Despertamiento de Guatemala":

hace siglos, una poderosa raza de personas vivía en los valles de Motagua y por cientos de millas a lo largo de las tierras costeras ahora desiertas de Guatemala y Honduras, que la United Fruit Company está acelerando hacia una civilización nueva. Las tierras bajas, que ahora tienen tales terrores para las tribus indias ignorantes y físicamente deficientes de Guatemala, no disuadieron a sus dignos antecesores de siglos atrás de dominar los problemas sanitarios de estos valles. Ellos sabían que estas tierras fecundas eran enteramente propicias para el abastecimiento cómodo y suntuoso de numerosas poblaciones (Adams, 1914: 203-204) $)^{9}$.

\footnotetext{
${ }^{8}$ La Atlántida y su "raza superior" que predominaba sobre los "nativos plagados de fiebre" centroamericanos es mencionada, entre otros, en Sands (1913).

${ }^{9}$ Lumis (1916: 281) alabó las tierras bajas en los alrededores de Motagua, "the Central American Euphrates", donde "los mayas construyeron su Mecca. Eran siempre habitantes de 
A través de tales formulaciones, los jefes de UFCo se autoestilizaban como seguidores de la raza atlante, aspirando a civilizar a los mayas de nuevo, a obligarles a realizar un trabajo regular y otorgarles todas las comodidades de la vida urbana. Gracias a la United Fruit Co., la selva volvería a ceder ante los campos y jardines, remplazando el cultivo original, el maíz, por el del plátano. A la vista de las ruinas de la "metrópoli antigua" de Quiriguá se construyó un hospital moderno y espacioso, considerado por muchos el mejor en Centroamérica, como la encarnación de la nueva etapa civilizadora ${ }^{10}$.

Figura 3. Hospital de la United Fruit Company en Quiriguá ${ }^{11}$

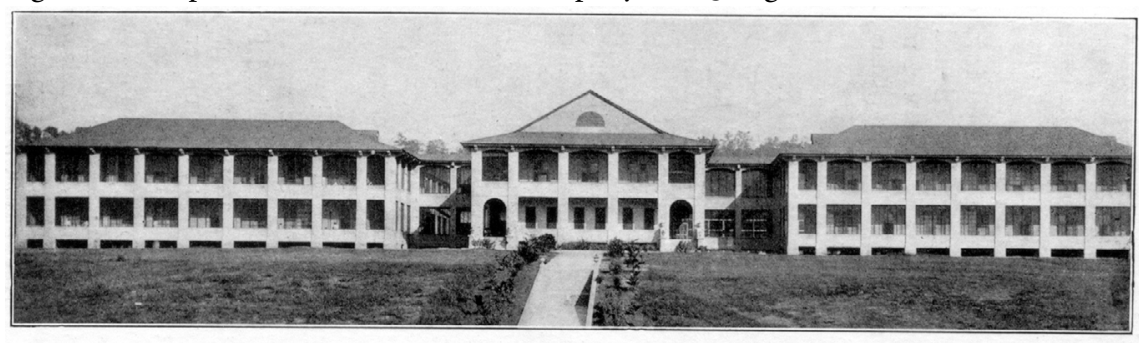

UNITED FRUIT COMPANY HOSPITAL IN QUIRIGUA

This magnificent hospital, erected and fitted at an expense exceeding $\$ 100,000$, stands in what was an uninhabited wilderness only a few years ago. Not far away are the famous ruins of Quirigua, whose rise and fall are shrouded in mystery

Fuente: (Adams, 1914)

El tema de la lucha de los arqueólogos con la selva aterradora, que amenazaba constantemente con devorar de nuevo las estructuras arquitectónicas ya limpias, se integraba muy bien en el discurso de la UFCo, cuyo fundamento era la subyugación y mejora de la naturaleza bárbara, sin mencionar las deplorables condiciones sociales en la región (Holme, 2013). También la ostentación del conocimiento experto de parte de los mayistas, que en ese tiempo remplazaron el criterio estético por el "científico" para evaluar la cultura maya, respondía al enfoque tecnócrata que marcaba el discurso estadounidense de este tiempo y validaba el de la compañía. Poseyendo una habilidad rara -el saber leer los

las tierras bajas, dejando las altas mesetas a los cacchiquel, quiche y zutuhil y otras tribus que no construían monumentos."

${ }^{10}$ Sylvanus Morley repetidamente anotaba en sus diarios la limpieza y modernidad del hospital en Quiriguá; en 1915, se construyó a su lado un campo de golf (Brunhouse, 1971).

${ }^{11}$ Hospital de la United Fruit Company en Quiriguá. Este magnífico hospital, construido y adecuado con un presupuesto que sobrepasaba los $\$ 100,000$ (USD), se encuentra en lo que hasta hace unos años era terreno salvaje inhabitado. No muy lejos están ubicadas las famosas ruinas de Quirigúa, cuyo auge y caída están cubiertos en misterio (Traducción del editor). 
jeroglifos mayas- los especialistas cultivaban el sentido de misterio alrededor del pasado maya, acentuando así su propia excepcionalidad y añadiendo valor a los resultados de sus empeños. Como escribió William Holmes: "Cada uno de los grandes monolitos tallados es más enigmático que la esfinge egipcia. No hay un atajo para el desvelamiento de su historia, y la arqueología debe asumir esta tarea tediosa pero fascinante" (Holmes, 1916: 269). En sus reportes, Hewett describió repetidamente al trabajo arqueológico como una "batalla" con varios tipos de dificultades, desde los obstáculos técnicos hasta los naturales y administrativos (Hewett, 1915: 89).

También el autor estadounidense de libros de viajes populares, Frank Carpenter, escribió sobre las enigmáticas ruinas, "hundidas y olvidadas tantos centenares, y ahora casi a tiro de piedra de las casas modernas de los oficiales y empleados de la compañía. [...] Los restos de la civilización antigua y la evidencia de una gran industria moderna pueden verse a lado y lado en Quiriguá” (Carpenter, 1930: 158-160). A la vez, continuaba el esfuerzo por buscar las raíces de los Estados Unidos en los sitios mayas. Los arqueólogos construían la imagen de "similitud general cultural" entre los habitantes de México, Centroamérica y Perú, pero también en los centros culturales norteamericanos, como las llanuras norteamericanas o la costa californiana, "el umbral norte del Anahuac", en las palabras de Edgar Lee Hewett (1936: $45)^{12}$. Ya durante la primera temporada de trabajo visitó las ruinas el enviado estadounidense en Guatemala, William Sands, confirmando el interés gubernamental en esta obra aparentemente académica (Hewett, 1910: 15).

En 1914, durante la última temporada de la SAA en Quiriguá, la investigación contribuyó aún más al fortalecimiento de la narración identitaria estadounidense y a sus ambiciones hegemónicas en el sur del continente; y al mismo tiempo, le brindó reconocimiento público y remuneración financiera a su director, Hewett. Para la Exhibición Panamá-California, que estaba en proceso de preparación y tuvo lugar en 1915 en San Diego, California, y para celebrar la terminación del canal de Panamá, su equipo procuró realizar moldeados de las estelas y estatuas más espectaculares. En esta ocasión, en vez del papel maché que usó Maudslay, se probó con éxito el hule sintético,

${ }^{12}$ También en la entrevista para New York Times (13-I-1912), Hewett no solamente prometió el desciframiento de la escritura maya "hasta la mitad del presente año" (sic), sino que también acentuó las similaridades "aparentes" entre los mayas y los zuñis del Suroeste norteamericano, incluso buscando analogías entre los jeroglifos mayas y las pinturas de arena de los habitantes indígenas del Suroeste. Esta entrevista provocó una crítica considerable por parte de Alfred Tozzer y otros arqueólogos prominentes de este tiempo (Fowler, 1999). 
produciendo reproducciones más exactas, y a la vez confirmando la supremacía de la tecnología americana sobre la europea (los moldeados hasta hoy día se conservan en el Museo del Hombre de San Diego) (Viella, 2012; Hewett, 1915). Al mismo tiempo, los artefactos más fácilmente transportables de Quiriguá eran llevados no solamente a los museos estadounidenses, sino también al hotel de la UFCo en Quiriguá, donde muchas de esas piezas y artefactos fueron destruidos por un incendio masivo en 1929 (Brunhouse, 1971: 128-129).

Al igual que la Escuela de Arqueología Americana, la UFCo hacía blasón de su involucramiento en Quiriguá. No solamente los arqueólogos ponían en sus textos notas de agradecimiento por la asistencia de parte del directorado de la compañía, sino que pasaban por las ruinas huéspedes prominentes. En marzo de 1912 las visitó brevemente el Secretario de Estado norteamericano Philander Knox, en viaje hacia Honduras. Ahí, Knox iba a firmar un convenio en Tegucigalpa para la UFCo, de extensiones impositivas y regalías diversas, que otorgaba el dictador Manuel Bonilla como agradecimiento por la colaboración de la empresa en el derrocamiento del presidente Miguel Dávila (Schávelzon, 1988: 173). Sylvanus Morley anotó en su diario que en anticipación del "gran día” de la llegada del representante estadounidense, se limpiaron carreteras alrededor de los más importantes monumentos, para facilitar su observación (Morley, 1955) ${ }^{13}$.

Los diarios de Sylvanus Morley de esos años relatan un constante flujo de visitantes, entre ellos empleados de la UFCo, oficiales militares, hombres de negocios y guatemaltecos ricos, pero reportes de los arqueólogos y de los viajeros mismos continuamente presentaban a Quiriguá como "virgen”, casi no visto por los humanos desde su abandono ${ }^{14}$. En concordancia con la retórica de Stephens y Maudslay, Morley trataba de crear la impresión de que los conocimientos expertos de los arqueólogos en conjunción con la contribución financiera de la UFCo produjeron las "maravillas" de la reconstrucción, afirmación que contenía una punzada contra los gobiernos centroamericanos, incapaces de llevar a cabo tales inversiones intelectuales o materiales.

También es interesante mencionar que las mismas élites guatemaltecas aceptaban e interiorizaban esta retórica y mostraban su gratitud a la UFCo y

\footnotetext{
${ }^{13}$ Transcripción mecanografiada de los diarios originales de Morley, preservada en el Archive of the American Philosophical Society.

${ }^{14}$ La imagen de Quiriguá "no visitada" hasta los tiempos de Stephens está en la entrevista ya citada de Hewett para New York Times (13-I-1912, 1).
} 
los arqueólogos norteamericanos por "salvar" su pasado. Esto lo comprueban los reportes de una excursión a Quiriguá, organizada en 1926 por la Sociedad de Geografía e Historia de Guatemala. El asombro de los participantes lo produjo tanto la misma finca bananera como la "metrópoli" maya:

Las bananeras comienzan a demostrar cómo el capital extranjero puede transformar nuestros eriales, de un modo que no saben los tímidos capitalistas nacionales. He ahí una ventaja y un peligro, una riqueza que no es nuestra, pero que sería miseria en poder nuestro. La compañía frutera norteamericana, arranca de ahí tesoros que nosotros hemos sido incapaces de extraer (Guillén, 1926).

El autor del reporte admiraba la puntualidad del servicio de trenes de la UFCo, las "inmensas plantaciones, con casas de confort y lujo, un Hospital modelo y jardines orientales", pero en especial el hecho de que "la Dirección de la Compañía Frutera tuvo la fineza de preparar el campo de observaciones, desyerbando los sitios y haciendo fácil el acceso al anfiteatro sagrado" (Guillén, 1926). Con todo, la imagen de la comunidad de Quiriguá como una ciudad casi utópica, donde el pasado heroico se unía con el presente para producir un futuro espléndido, contradice la documentación que testifica no solamente la explotación y la dureza de vida, sino también el racismo de la compañía hacia los peones de color en las fincas de la United Fruit Co. La alabanza de la antigüedad maya no prevenía la postura denigrante hacia sus "descendientes" (Colby, 2011: 119-120).

No se puede averiguar hasta qué grado las ambiciones y el discurso de sus primeros empleadores repercutieron en el futuro marco teórico de Sylvanus Morley. Aparentemente él no formulaba sus interpretaciones de modo enteramente utilitario; pero se pueden identificar algunos temas en los que obviamente repercutían sus experiencias tempranas, entre ellos su convicción de que era precisamente en las tierras bajas húmedas donde la civilización maya llegó a su florecimiento más espectacular, tanto como el interés de este investigador en la agricultura tropical precolombina. Esto queda patente en la Guía de las ruinas de Quiriguá, publicada en 1935, es decir, casi dos decenios después de su paso de la SAA a la Institución Carnegie de Washington, volviéndose el director de su programa maya durante el período en el que la UFCo todavía dominaba el terreno en los alrededores de Quiriguá y otras 
localidades, y también la política de los estados centroamericanos. En el libro, dedicado al "pueblo guatemalteco", repitió los argumentos fundamentales de la UFCo. El clima cálido y húmedo del Valle de Motagua, escribió Morley:

ha atraído al hombre moderno, como atrajo a los antiguos mayas. [...] Así se repite la historia. Hace dos mil años la sección de Quiriguá del valle del Montagua estaba cubierta de legítima selva primitiva. [...] Probablemente en los albores de la era cristiana, grupos de indios agricultores ocuparon la región y se dedicaron a talar la tierra con maíz. Durante el último siglo del Gran Periodo (aproximadamente hacia los ańos 790-889 después de Jesucristo) dicho centro fue abandonado y la gran mayoría de los habitantes de la comarca se trasladó a otra parte. [...] Más de mil años después, una gran compañía moderna, la United Fruit Company, buscando tierras adecuadas para el cultivo de otra gran planta alimenticia - el banana - desmontó el valle por segunda vez y lo destinó a sus faenas agrícolas (Morley, 1936).

\section{Las paradojas de la arqueología}

Al comenzar la Primera Guerra Mundial, el equipo de Santa Fe se retiró de Quiriguá. Como es bien sabido, durante la guerra y aún después de ella, Morley mismo operaba como el agente de la Oficina de Inteligencia Naval federal estadounidense en Guatemala y Yucatán, donde simultáneamente realizaba sus reconocimientos arqueológicos. Este hecho también testifica las variadas motivaciones que se hallaban detrás del respaldo oficial de las investigaciones de la prehistoria americana (Harris y Sadler, 2003). Mientras tanto, la arqueología maya estadounidense se expandía tanto cuantitativa como cualitativamente, gracias a las inversiones financieras institucionales y privadas, al refinamiento de métodos y técnicas de las excavaciones, y al aumento del personal académico. Dentro del marco de este dinámico desarrollo, el "parque natural” de Quiriguá perdió su carácter único y exclusivo, se tornó en una de muchas localidades similares y susceptibles de ser investigadas; sin embargo, la UFCo mantuvo vigentes las excavaciones y obras de reconstrucción en esta ciudad. En los años 1920 y 1930 estuvieron a cargo del Instituto Carnegie en Washington, con Sylvanus Morley como director, de manera que su comunicación con la compañía perduró y él no olvidaba dar sus gracias por el soporte continuo. 
Es interesante que no solamente para la UFCo, sino también para sus competidores en el campo de producción y comercio bananeros, la mayística mantuvo su atractivo. Aparentemente los emprendedores que aspiraban a fortalecer su influencia política, económica e intelectual, tanto en la región centroamericana como en la sociedad estadounidense, apreciaban la disciplina, por lo menos, como modo útil de autopresentación. En 1924 se fundó en Nueva Orleans -es decir, en el mismo foco del comercio bananero en los Estados Unidos- el Instituto Centroamericano de Investigación de la Universidad de Tulane (Middle American Research Institute of Tulane University). Se pudo establecer gracias a una donación financiera de Samuel Zemurray, fundador de la compañía Cuyamel Fruit (la más importante rival de la UFCo), aunque, según la narrativa oficial, la donación fue hecha por "un amigo anónimo de la Tulane University” (Blom y La Farge, 1926: 1; Argueta, 1989).

Bajo la dirección de William Gates, el Instituto Centroamericano de Investigación inició obras de reconocimiento en preparación de excavaciones en el área maya, para las que Zemurray facilitó el uso de equipo, tecnología y transporte. Una vez más, en la fundación de la institución y la selección de la localidad para las excavaciones obraban motivaciones muy personales, como la competición individual por prestigio en los círculos académicos y ante el público general. William Gates se enemistó con la Institución Carnegie y con Morley; por esto, trató de superarles en sus propios proyectos (Brunhouse, 1971: 197). Bajo los auspicios del Instituto Centroamericano, el danés Frans Blom y el antropólogo norteamericano Oliver La Farge emprendieron una expedición larga hacia Guatemala, Honduras y Chiapas (México) en 1925. También ellos podrían aprovechar, a través de todo su viaje, la infraestructura bananera ${ }^{15}$.

El reporte de Blom de su primera expedición documenta claramente la rivalidad institucional y los esfuerzos de los mayistas por destacar y revelar cosas todavía desconocidas, más lejanas y más enigmáticas: "Descubrimos veinticuatro ciudades en ruinas, hasta ahora no registradas por los científicos. [...] La obra que emprendimos en Centroamérica pondrá a Tulane University en el mapa como la que poseyera el departamento más grande en el país de

\footnotetext{
${ }^{15}$ Descripción de la expedición en Blom y La Farge, Tribes and Temples. Blom, de hecho, a finales de su viaje, a la vuelta al Puerto Barrios, visitó brevemente también Quiriguá, pero no incluyó esta información en su libro (Brunhouse, Frans Blom, Maya Explorer, Albuquerque, NM 1976, 60).
} 
estudios mayas" (Brunhouse, 1976: 58; véase también Schávelzon, 1982: 163-183). En 1926, Blom remplazó a Gates en el puesto de director del Instituto Centroamericano y, en los años subsecuentes, emprendió otras cuatro expediciones ${ }^{16}$. Entretanto, en 1929, la Cuyamel Fruit fue absorbida por UFCo y, cuatro años después, Zemurray asumió la dirección de la compañía. Su hija, Doris Zemurray Stone, se graduó en arqueología y se involucró activamente en las investigaciones en Centroamérica. Quizás a causa de la original orientación de Cuyamel Fruit en Honduras, ella también realizó sus excavaciones en este país, más que en Guatemala (Andrews y Lange, 1995; Doris Stone, 1976).

En el modo de presentar sus actividades en Centroamérica, tanto el Instituto Centroamericano como el Instituto Carnegie reconocían la retórica civilizatoria de los emprendedores frutales. Describían sus investigaciones más bien como actividades pedagógicas y civilizadoras, gracias a las cuales los habitantes locales pudieran apreciar el valor verdadero de los tesoros históricos en el suelo nacional. De hecho, en virtud de la ley de 1931, los sitios arqueológicos importantes en Guatemala fueron declarados monumentos nacionales y se estableció una sección arqueológica en el Museo Nacional (Schávelzon, 1978: 57). Precisamente, para el año 1931, el boletín Unifruitco -órgano informativo de la UFCo- describió a detalle la visita del dictador guatemalteco Jorge Ubico a Quiriguá. Viajó en el buque de vapor a Puerto Barrios, de ahí siguió en tren, pernoctó en el hotel y visitó también el hospital (Aliano, 2006: 38 ).

La visita aparentemente despertó el interés de Ubico por los artefactos mayas y su posible uso en su favor, para su propia propagación y para la corroboración del sentimiento nacionalista. El arqueólogo noruego Gustav Stromsvik recordó que, en 1932, Ubico anunció su intención de retirar algunas de las estelas de Quiriguá para colocarlas en los parques en la capital del país. Aunque Sylvanus Morley, en este tiempo el director del proyecto maya de la Institución Carnegie, comenzó las obras de limpieza y reparación de los monumentos, al final logró de convencer al dictador guatemalteco de dejarles en el lugar (Long, 1950: 242).

En los años cuarenta, la "enfermedad de Panamá", que afectaba a los bananos, alcanzó también a las plantaciones de UFCo en los alrededores de

\footnotetext{
${ }^{16}$ La asistencia de parte de la UFCo a los arqueólogos es descrita en detalle por Jens Yde, "A preliminary report of the Tulane University - Danish National Museum Expedition to Central America 1935", Maya Research 3:1 (1936), 25-37.
} 
Quiriguá, y la compañía vendió el terreno a un hacendado guatemalteco, quien afortunadamente decidió mantener el "parque tropical" en operación (Brunhouse, 1971: 288). Sin embargo, la UFCo mantuvo su conexión con la mayística y, en 1946, comenzó de nuevo una excavación de gran escala en otras ruinas en Guatemala, llamadas Zaculeu, con la participación de especialistas de gran renombre en la comunidad académica y relacionados con varias de las instituciones más importantes de los EE.UU. Además de realizarse una excavación minuciosa tanto en la ciudad como en sus alrededores, se lograron rehacer varios edificios, con sus plataformas, escaleras, muros y hasta parte de los techos, transformando a la localidad en un popular destino turístico. Entre los objetivos de la empresa estaba también, sin duda, el de hacer publicidad para la compañía bananera, criticada severamente en Guatemala en ese momento por oponerse a los aumentos de salarios y al nuevo Código de Trabajo. Para estos fines la UFCo se aprovechaba de su propio instrumento propagandístico, la Oficina de Información Centroamericana (Middle American Information Bureau), que publicaba folletos y boletines, emitía programas de radio y organizaba conferencias sobre Zaculeu y las excavaciones, además de apoyar a la compañía en la publicación de libros especializados (Boggs, 1946; Woodbury y Trik, 1954). Con todo, en este proyecto, como en los anteriores, se suponía automáticamente que la excavación debía hacerse con todo el rigor científico de la arqueología de la época (Schávelzon, 1988: 174). A la vez, se reaccionaba a la intensificada demanda en Guatemala misma por el rescate del patrimonio cultural del pueblo y de la cultura indígena tradicional, provocado por los ideales del nacionalismo.

En lo que toca a Quiriguá, persistía su atractivo para los arqueólogos, mientras que la producción de bananos se recuperaba en sus alrededores. En 1973 comenzó un proyecto monumental de excavaciones, esta vez bajo los auspicios de la Universidad de Pensilvania, en cooperación con el gobierno guatemalteco (Ashmore, 1984; Sharer y Coe, 1979; Sharer, 1978). Antes de comenzar la investigación, se confirmó por contrato el derecho del estado de Guatemala a todos los objetos hallados en la localidad y ésta fue proclamada "patrimonio del pueblo guatemalteco". El involucramiento activo del estado guatemalteco provocaba también el creciente atractivo de las ruinas precolombinas para los turistas. Esta motivación, por supuesto, repercute en las interpretaciones científicas, ya que acentúa la otredad, el exotismo y la excepcionalidad de los mayas. El problema de la representación de la antigüedad 
también se vio reflejado en la película experimental de Leonardo Katz, Paradox (2001), que puso en contraste explícito la producción mecanizada agrícola de gran tamaño y la engańosa tranquilidad de las ruinas, para "contemplar la relación entre el pasado monumental y el presente degradado de Guatemala y América Latina" (Lerner, 2005: 83; Katz, 2004).

El papel jugado por la UFCo en la promoción y dirección de trabajos arqueológicos en Centro América debe entenderse como parte de su política hegemónica en dichos países, en los que sus intereses rebasaron lo económico, entrando de lleno en lo político y en lo social. Hasta qué grado este involucramiento en el estudio de la arqueología maya fue más allá del apoyo financiero es difícil de averiguar. Los archivos de la compañía United Fruit Co. no están abiertos al público y gran parte de la documentación para distritos latinoamericanos se destruyó, a propósito, cuando en 1984 la compañía se transformó en la nueva marca United Brands (Colby, 2011: 12-13).

Todo lo escrito previamente no era motivado por una intención de poner en duda la sinceridad de los esfuerzos de los arqueólogos, muchos de los cuales invertían sus fuerzas y conocimientos con la certeza de que estaban haciendo ciencia pura, de alta calidad. Hay que tomar en cuenta, sin embargo, que en realidad no eran los sabios en la torre de marfil, sino más bien actores políticos; que los protagonistas de varios grupos de intereses, tanto como las élites gobernantes, se apropiaban de informaciones, teorías e interpretaciones científicas y las ajustaban a usos peculiares, muchas veces muy lejanos a los contextos originales en los que se habían originado, imponían agendas e influían en los mismos procesos de producción y reconfiguración de saberes. El desarrollo de la disciplina tampoco fue lineal y fácil, tal y como se presenta a veces en los manuales sumarios, sino más bien fue un resultado de debates multilaterales, choques y pugnas en que se reflejaban tanto las inspiraciones individuales de los sabios como las rivalidades políticas y económicas, algunas globales, algunas muy locales. 


\section{Bibliografía citada}

Adams, Frederick Upham, (1914) Conquest of the Tropics: the story of the creative enterprises conducted by the United Fruit Company. Garden City, New York: Doubleday Page \& Co.

Aguirre, Robert, (2005) Informal Empire: Mexico and Central America in Victorian Culture. Minneapolis: University of Minnesota Press.

Aguirre, Robert, (2012) “The Work of Archaeology: The Maudslays in Late Nineteenth-century Guatemala", en Mackentun Gesa y Klaus Hock (eds.), Entangled Knowledges: Scientific Discourses and Cultural Difference. Münster: Waxmann. pp. 231-247.

Alford, William V., (1899) "Fragments from Pre-Historic America. The Wonderful Ruins of Quirigua in Central America", en Home Magazine. 13:2, pp. 143-148.

Aliano, David, (2006) "Curing the Ills of Central America: The United Fruit Company's Medical Department and Corporate America's Mission to Civilize (1900-1940)", en EIAL: Estudios Interdisciplinarios de America Latina y el Caribe. 17:2, pp. 35-60.

Alvarenga Ventulo, Patricia, (2015) "Contemplar y poseer. El poder de la mirada en la disputa por la apropiación de objetos y monumentos de las culturas antiguas de Centroamérica", en Revista de Historia 71:1, pp. 13-39.

Andrews, E. Wyllys y Frederick W. Lange, (1995) "In Memoriam Doris Zemurray Stone, 1909-1994”, en Ancient Mesoamerica. 6, pp. 95-99.

Argueta, Mario R., (1989) Bananos y política: Samuel Zemurray y la Cuyamel Fruit Company en Honduras. Tegucigalpa: Editorial Universitaria.

Ashmore, Wendy, (1984) "Quirigua Archaeology and History Revisited”, en Journal of Field Archaeology. 11:4, pp. 365-386.

Blackiston, A. Hooton, (1911) "Quirigua", en Records of the Past. 10:2, pp. 59-76.

Blom, Frans y Oliver La Farge, (1926) Tribes and Temples: A Record of the Expedition to Middle America Conducted by the Tulane University of Louisiana in 1925. New Orleans: Tulane Universit.

Boggs, S. H., (1946) Guide to the Ruins of Zacaleu. (1946). New York: Middle America Information Bureau/United Fruit Company.

Brunhouse, Robert L., (1971) Sylvanus G. Morley and the World of the Ancient Mayas. United States of America: University of Oklahoma Press. 
Brunhouse, Robert L., (1976) Frans Blom, Maya Explorer. Albuquerque: University of New Mexico Press.

Brunhouse, Robert L., (1989) En busca de los mayas: Los primeros arqueólogos. trad. Jorge Ferreiro. México: FCE.

Carpenter, Frank G., (1930) Carpenter's World Travels: Lands of the Caribbean. Garden City, New York: Doubleday Page \& Co.

Catherwood, Frederick, (1844) Views of Ancient Monuments in Central America, Chiapas and Yucatan. London: F. Catherwood.

Chandler, John R., (1896) "Ruins of Quiriguá", en Science. 3:75, pp. 832833.

Chinchilla Mazariegos, Oswaldo, (1994) "Nacionalismo y arqueología en la Guatemala de la Independencia“, en Juan Pedro Laporte y Héctor Escobedo (eds.), VII Simposio de Investigaciones Arqueológicas en Guatemala, 1993. Guatemala: Museo Nacional de Arqueología y Etnología. pp. 1-9.

Colby, Jason M., (2011) The Business of Empire: United Fruit, Race, and U. S. Expansion in Central America. Ithaca: Cornell University Press.

Díaz-Andreu, Margarita, (1999) "Nacionalismos y arqueología. Del viejo al nuevo mundo", en Revista do Museu de Arqueologia e Etnologia. Suplemento 3, pp. 161-180.

Dietler, Michael, (1994) “'Our ancestors the Gauls': archeology, ethnic nationalism, and the manipulation of Celtic identity in modern Europe”, en American Anthropologist. 96, 584-605. doi:10.1525/ aa.1994.96.3.02a00090

Dosal, Paul, (1993) Doing Business with the Dictators: A Political History of United Fruit in Guatemala, 1899-1944. Wilmington: Scholarly Resources.

Evans, R. Tripp, (2004) Romancing the Maya: Mexican Antiquity in the American Imagination, 1820-1915. Austin: University of Texas Press.

Fowler, Don D., (1999) "Harvard vs. Hewett: The Contest for Control of Southwestern Archaeology, 1904-1930", en Alice B. Kehoe y Mary Beth Emmerichs (eds.), Assembling the Past: Studies in the Professionalization of archaeology. Albuquerque: Univeristy of New Mexico Press. pp. 213-227.

Fowler, Don D., (2000) A Laboratory for Anthropology: Science and Romanticism in the American Southwest, 1846-1930. Albuquerque: University of 
New Mexico Press.

Fowler, Don D., (2003) "E. L. Hewett, J. F. Zimmerman, and the Beginnings of Anthropology at the University of New Mexico, 1927-1946", en Journal of Anthropological Research. 59:3, pp. 305-327.

Godoy, Ricardo, (1977) "Franz Boas and his plans for an international School of American Archaeology and Ethnology in Mexico", en International Journal of the History of the Behavioral Sciences. 13:1, pp. 22-42.

Graham, Ian, (1963) "Juan Galindo: Enthusiast”, en Estudios de cultura maya 3. pp. 11-35.

Graham, Ian, (2002) Alfred Maudslay and the Maya. Oklahoma: University of Oklahoma Press.

Guillén, Flavio, (1926) "De Guatemala a Río Dulce, pasando por Quiriguá", en Anales de la Sociedad de Geografía e Historia. 3:3, pp. 235-243.

Harris, Charles H. y Luis R. Sadler, (2003) The Archaeologist Was a Spy: Sylvanus G. Morley and the Office of Naval Intelligence. Albuquerque: University of New Mexico Press.

Harvey, Bruce A., (2001) American Geographics: U.S. National Narratives and the Representation of the Non-European World, 1830-1865. Stanford: Stanford University Press.

Hewett, Edgar L., (1910) "Report to the Managing Committee of the School of American Archaeology, 1910", en Bulletin of the Archaeological Institute of America. 2:1, pp. 15-27.

Hewett, Edgar L., (1912a) “The Excavation of Quirigua, Guatemala, by the School of American Archaeology", en Proceedings of the XVIIIth International Congress of Americanists. London: Harrison and Sons. pp. 238-240.

Hewett, Edgar L., (1912b) “The Excavations at Quirigua”, Bulletin of the Archaeological Institute of America. 3, pp. 163-171.

Hewett, Edgar L., (1915) "Ancient America at the Panama-California Exposition”, en Art and Archaeology. 2:3, pp. 65-90.

Hewett, Edgar L., (1916) "Latest Work of the School of American Archaeology at Quirigua”, en Frederick Webb Hodge y Ella Leary (eds.), Holmes Anniversary Volume: anthropological essays presented to William Henry Holmes in honor of his seventieth birthday. Washington: J.W. Bryan Press. pp. 157-162.

Hewett, Edgar L., (1936) Ancient life in Mexico and Central America. 
Indianapolis: Bobbs-Merrill Co.

Holme, Justin, (2013) Creating Wealth Out of the World's Waste Spots: The United Fruit Company and the Story of Frontiers, Environment, and American Legacy, 1899-1930, tesis para obtener el grado de maestría. Canada, Department of History and Classical Studies, McGill University. Recuperado de: http://digitool.library.mcgill. ca/webclient/StreamGate?folder_id=0\&dvs=1547128609626 399 [fecha de consulta:8 10 de enero de 2019]

Holmes, William H., (1916) "Masterpieces of Aboriginal American Art V: The Great Dragon of Quirigua”, en Art and Archaeology. 6:6, pp. 269278.

Katz, Leandro, (2004) “The Catherwood Project”, en Patrick Frank (ed.), Readings in Latin American Modern Art. New Haven: Yale University Press. pp. 230-232.

Keen, Benjamin, (1971) The Aztec Image in Western Thought. Brunswick. New Jersey: Rutgers University Press, New.

Kennedy, Dane, (2014) "Introduction: Reinterpreting Exploration", en Dane Kennedy (ed.), Reinterpreting Exploration: The West in the World.

Oxford: University of Oxford Press. pp. 1-19.

Lenz, William E., (2012) Ruins, Revolution, and Manifest Destiny: John Lloyd Stephens Creates the Maya. New york: Peter Lang.

Lerner, Jesse, (2005) "The Paradoxes of Quiriguá, en Journal of Film and Video. 57:1-2, pp. 78-83.

Lewis, Nancy Owen y Kay Leigh Hagen, (2007) A Peculiar Alchemy: A Centennial History of SAR. Santa Fe, Nuevo Mexico: School for Advanced Research.

Long, Boaz (ed.), (1950) Morleyana: a collection of writings in memoriam Sylvanus Griswold Morley, 1883-1948. Santa Fe: School of American Research/Museum of New Mexico.

Looper, Matthew, (2003) Lightening Warrior: Maya Art and Kingship at Quirigua. Austin: University of Texas Press.

Lumis, Charles F., (1916) "Where the Stones Come to Life", en Art and Archaeology. 4:6, pp. 281-290.

Maudslay, Alfred P., (1886) "Exploration of the Ruins and Site of Copan, Central America", en Proceedings of the Royal Geographical Society and Monthly Record of Geography. 8:9 (1886), pp. 568-594. 
Maudslay, Alfred P., (1899-1902) Archaeology, 4 vols., en F. Duncane Godman y Osbert Salvin, Biologia Centrali-Americana, or, Contributions to the Knowledge of the Fauna and Flora of Mexico and Central America. London: R.H. Porter/Dulau \& Co.

Maudslay, Anne Cary y Alfred Percival Maudslay, (1899) A Glimpse at Guatemala and some notes on the Ancient Monuments of Central America. London: John Murray.

Maxwell, Anne (2000) Colonial Photography and Exhibitions: Representations of the "Native" and the Making of European Identities. London/New York: Leicester University Press.

Morley, Sylvanus G., (1912) "Quirigua, an American Town 1400 Years Old: Glimpses of an Extinct American Civilization”, en Scientific American. 107:5, pp. 96-97, 105.

Morley, Sylvanus G., (1913) "Excavations at Quiriguá, Guatemala”, en National Geographic. 24:3, pp. 339-361.

Morley, Sylvanus G., (1923) "Diary of Sylvanus Griswold Morley, 1912, Quirigua Field Notes", en Archive of the American Philosophical Society. Fondo Mss.B.M828 (Sylvanus Griswold Morley Diaries). Vol. 15. pp. 85-86.

Morley, Sylvanus G., (1936) Guía de las ruinas de Quiriguá, trad. Adrián Recinos. Washingon: Carnegie Institution.

Nilsen, Micheline, (2011) Architecture in Nineteenth Century Photographs: Essays on Reading a Collection. Farnham: Routledge.

Ortega y Medina, Juan, (1962) "Monroismo arqueológico: Un intento de compensación de americanidad insuficiente", en Ensayos, tareas y estudios históricos. Xalapa: Universidad Veracruzana. pp. 37-86.

Recinos, Adrian, (1953-54) "Evocación del viaje de Scherzer y Wagner a Centroamérica, 1853-54", en Anales de la sociedad de geografia e historia de Guatemala. 27, pp. 137-141.

Rutsch, Mechthild, (2000) "El patrimonio arqueológico mexicano y la International School of American Archaeology and Ethnology", en Ludus Vitalis. Revista de filosofía de las ciencias de la vida. 8:15, pp. 131-164.

Salvatore, Ricardo D., (2016) Disciplinary conquest: U.S. scholars in South America, 1900-1945. Durham, NC: Duke University Press.

Sands, W. F., (1913) "Mysterious Temples of the Jungle: The Prehistoric Ruins 
of Guatemala", en National Geographic. 24:3, pp. 325-338.

Schávelzon, Daniel, (1978) "El saqueo arqueológico de Guatemala", en Antropología e Historia: Boletin del Instituto Nacional de Antropología e Historia, 3:22, pp. 57-62.

Schávelzon, Daniel, (1982) "Frans Blom: Crónica de su expedición a México y Guatemala en 1925", en Anales de antropología 19, pp. 163-183.

Schávelzon, Daniel, (1988), "Las excavaciones en Zaculeu (1946-1950): una aproximación al análisis de la relación entre arqueología y política en América Latina“, en Nicholas J. Saunders - Olivier de Montmollin (eds.), Recent Studies in pre-Columbian archaeology. Oxford: Univeristy of Oxford Press. T. 1, pp. 167-190.

Scherzer, Karl, (1855) "Ein Besuch bei den Ruinen von Quiriguá im Staate Guatemala in Central-Amerika”, en Sitzungsberichte der kaiserlichen Akademie der Wissenschaften in Wien. 16, pp. 228-240.

Scherzer, Karl, (1936) “A visit to Quiriguá”, en Maya Research 3:1, pp. 82101.

Schoonover, Thomas David, (1991) The United States in Central America, 1860 - 1911: episodes of social imperialism and imperial rivalry in the world system. Durham: Duke University Press

Sharer, Robert J., (1978) "Archaeology and History at Quirigua, Guatemala", en Journal of Field Archaeology 5, pp. 51-70.

Sharer, Robert J. y William R. Coe, (1979) "The Quirigua Project: Origins, Objectives and Research in 1973 and 1974”, en Wendy Ashmore (ed.), Quirigua Reports I. Philadelphia: University of Pennsylvania Press. pp. 1-11.

Sharer, Robert J. y Loa P. Traxler, (2012) "Copan and Quirigua: Shifting Destinies in the Southeastern Maya Lowlands", en Contributions in New World Archaeology. 4, pp. 139-156.

Shields, Duncan, (2015) "Multiple collections and fluid meanings: Alfred Maudslay's archaeological photographs at the British Museum", en Elizabeth Edwards, Christopher Morton (eds.), Photographs, Museums, Collections: Between Art and Information. London/New York: Bloomsbury Academic. pp. 27-46.

Stephens, John Lloyd, (1971) [1841] Incidentes de Viaje en Centroamérica, Chiapas y Yucatán, trad. Benjamin Mazariegos Santizo. San José: Editorial Universitaria Centroamericana. 2 vols. 
Stoll, Otto, (1886) Guatemala: Reisen und Schilderungen aus den Jahren 18781883. F.A. Leipzig: Brockhaus.

Stone, Doris , (1976) Pre-Columbian Man Finds Central America. Cambridge, Ms: Cambridge University Press.

Thompson, John Eric Sidney, (1936) “A Note on Scherzer’s Visit to Quiriguá, en Maya Research. 3:3, pp. 330-331.

Trigger, Bruce, (1984) "Alternative Archaeologies: Nationalist, Colonialist, Imperialist", en Man. 19:3, pp. 355-370.

Urías Horcasitas, Beatriz, (2001), "Franz Boas en México", en Historia y grafía. 16, 209-248.

Vargas, Juan Carlos, (2008) Tropical Travel. The Representation of Central America in the Nineteenth Century. San José: University of Costa Rica.

Viella, Khristaan D., (2012) "Simulacrum, simulacrum on the wall: casts of the ancient Maya monuments of Quiriguá", en Pasatiempo. April 27 - May 3, pp. 36-40.

Woodbury, Richard B. y Aubrey S. Trik, (1954) The Ruins of Zaculeu. New York: United Fruit Company.

Yde, Jens, (1936) "A preliminary report of the Tulane University - Danish National Museum Expedition to Central America 1935”, en Maya Research. 3:1, pp. 25-37.

\section{Fuente de las imágenes}

Adams, Frederick Upham, (1914) Conquest of the Tropics: the story of the creative enterprises conducted by the United Fruit Company. Garden City, New York: Doubleday Page \& Co.

Library of Congress (1908) "Guatemala, Quiriguá, en Library of Congress. [en línea]. Washington, recuperado de: https://www.loc.gov/ item/2016821509/ [consultado el día 21 de junio de 2019)

Library of Congress (1908) "Guatemala, Quiriguá stone image", en Library of Congress. [en línea]. Washington, recuperado de: https://www.loc. gov/item/2016821509/ [consultado el día 21 de junio de 2019) 